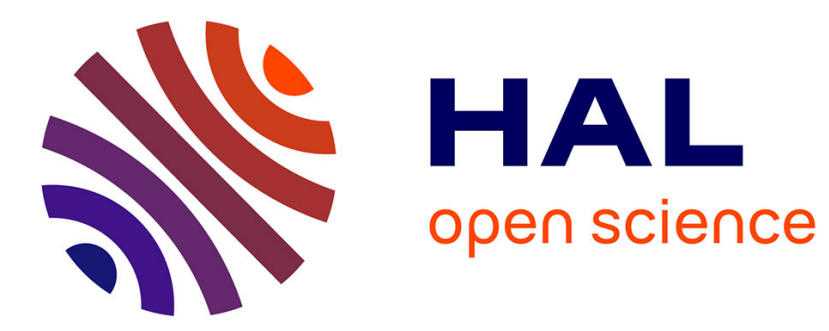

\title{
An Efficient Tool for Automatic Delimitation of Moroccan Coastal Upwelling Using SST Images
}

Ayoub Tamim, Khalid Minaoui, Khalid Daoudi, Hussein Yahia, Abderrahman Atillah, Driss Aboutajdine

\section{- To cite this version:}

Ayoub Tamim, Khalid Minaoui, Khalid Daoudi, Hussein Yahia, Abderrahman Atillah, et al.. An Efficient Tool for Automatic Delimitation of Moroccan Coastal Upwelling Using SST Images. IEEE Geoscience and Remote Sensing Letters, 2014, pp.5. hal-01078655

\section{HAL Id: hal-01078655 \\ https://hal.inria.fr/hal-01078655}

Submitted on 29 Oct 2014

HAL is a multi-disciplinary open access archive for the deposit and dissemination of scientific research documents, whether they are published or not. The documents may come from teaching and research institutions in France or abroad, or from public or private research centers.
L'archive ouverte pluridisciplinaire HAL, est destinée au dépôt et à la diffusion de documents scientifiques de niveau recherche, publiés ou non, émanant des établissements d'enseignement et de recherche français ou étrangers, des laboratoires publics ou privés. 


\title{
An Efficient Tool for Automatic Delimitation of Moroccan Coastal Upwelling Using SST Images
}

\author{
Ayoub Tamim, Khalid Minaoui, Khalid Daoudi, Hussein Yahia, Abderrahman Atillah, and Driss Aboutajdine
}

\begin{abstract}
An unsupervised classification method is developed for the coarse segmentation of Moroccan coastal upwelling using the Sea Surface Temperature (SST) satellite images. The algorithm is started with the generation of c-partitioned labeled image using Otsu's method for the purpose of finding regions of homogenous temperatures. Then two well-known validity indices are used to select the c-partition which best reproduce the shape of upwelling area. A region-growing algorithm is developed that is used to remove the noisy structures in the offshore waters not belonging to the upwelling area. The algorithm is used to provide a seasonal variability of upwelling activity in the southern Moroccan Atlantic coast using 70 SST images of the years 2007 and 2008. The performance of the proposed methodology has been validated by an oceanographer, showing its effectiveness for automatic delimitation of Moroccan upwelling region.
\end{abstract}

Keywords-Sea surface temperature image, upwelling, unsupervised classification, Otsu's method, Region-growing algorithm, Moroccan atlantique coast.

\section{INTRODUCTION}

$\mathbf{M}$ OROCCAN coastal upwelling is a part of the canary current system, characterized by spatially variable and temporally persistent upwelling activity almost all around the year [1]. In fact, under the influence of northeasterly wind and the persistence of Ekman transport along the Moroccan coast, the surface waters are replaced by cold, less salty and nutrient-rich deep waters, reflecting the signature of the upwelling phenomenon. At this point, the detection of upwelling has a fundamental importance in the study of productivity enhancement and associated fish management [5].

The SST images obtained from Infrared satellite sensor are frequently used to study the main frontal boundary, separating the cold water near the coast and warmer offshore waters [12]. As pointed out by Bakun [2], the fronts detected in upwelling region are usually associated to a convergence zone, characterized by high primary productivity.

In the literature, several numerical studies have addressed the problem of automatic identification of upwelling zone in SST images. Current approaches are mainly based on the histogram-based separation [13], where the bimodality of SST histogram is interpreted to represent two different water

Ayoub Tamim, Khalid Minaoui and Driss Aboutajdine are with the LRIT Laboratory, Associated Unit to the CNRST-URAC n²9, Mohammed V-Agdal University, Rabat, Morocco (E-mail: a.tamim@ @frr.um5a.ma; khalid.minaoui@fsr.ac.ma; aboutaj@fsr.ac.ma ).

Khalid Daoudi and Hussein Yahia are with the INRIA Institute of Bordeaux Sud-Ouest (GEOSTAT team), Talence, France (E-mail: khalid.daoudi@inria.fr; hussein.yahia@inria.fr).

Abderrahman Atillah is with the Royal Centre of Remote Sensing (CRTS), Rabat, Morocco (E-mail: atillah@crts.gov.ma) masses. The neural network discussed in [6] is shown to be an effective tool to quantitatively reproduces the shape of upwelling area. In fact, the neural network is trained based on the $k$-means clustering results and a statistical criterion is generated to check the existence of upwelling water in each labeled image. Another technique, which relies on the detection of upwelling regions using the Fuzzy $c$-means algorithm [12], has also been addressed in order to delineate the upwelling areas using the fuzzy strategy.

In our previous work [19], two unsupervised classification techniques, Otsu and Fuzzy $c$-means, belonging respectively to two different strategies of clustering, hard and fuzzy strategy, are used to detect the area covered by the upwelling waters. The latter starts by generating a labeled image from the SST image, using any of the two proposed methods (Otsu or Fuzzy $c$-means algorithms) with 2 clusters, in order to provide two homogenous groups, corresponding to upwelling and nonupwelling regions. Next, the region-growing process is used to automatically remove and filter the remaining pixels in offshore waters not belonging to the upwelling. The approach is applied on 66 daily and weekly SST images covering the years 2004, 2005, 2007 and 2009, and the results are validated by an oceanographer. The previous work [19] is shown to be a promising tool for automatic extraction of Moroccan coastal upwelling, using fast and well-known segmentation algorithms.

However, the preceding approach suffers from the following shortcomings: 1) the number of clusters is subjectively adjusted to 2 according to the priori knowledge of the study area provided by the oceanographer; 2) the database used throughout the study is taken randomly during 4 years, and may contain images with a heavy cloud cover that can yield to erroneous results in the upwelling detection procedure; 3 ) no seasonal variability of upwelling activity is made by the authors.

For this purpose, the current methodology overcomes the mentioned difficulties and gives accurate results for automatic detection of the main upwelling front in SST images. Furthermore, the algorithm is used to provide a seasonal variability of upwelling activity along the study area.

This paper is organized as follows: Section II presents the database and the area of study used throughout this work. Section III describes the methodology for the automatic delimitation of upwelling area, while section IV reports the experimental results and analysis. Finally, a conclusion is drawn in section $\mathrm{V}$.

\section{STUdy AREA AND DATA}

This research focuses on the southern Moroccan Atlantic coast $\left(20^{\circ} 50^{\prime}-27^{\circ} 52^{\prime} \mathrm{N}\right.$ and $\left.13^{\circ} 10^{\prime}-20^{\circ} 10^{\prime} \mathrm{W}\right)$ using a 


\begin{tabular}{|c|l|l|l|}
\hline Seasons & Month & Weekly (2008) & Daily (2007) \\
\hline \multirow{3}{*}{ Winter } & December & $43,44,45,46$ & 24,31 \\
\cline { 2 - 4 } & January & $1,2,3,4$ & $01,02,20$ \\
\cline { 2 - 4 } & February & $5,6,7$ & \\
\hline \multirow{3}{*}{ Spring } & March & $8,9,10,11$ & \\
\cline { 2 - 4 } & April & $12,13,14,15$ & 12,27 \\
\cline { 2 - 4 } & May & $16,17,18,19$ & 11,12 \\
\hline \multirow{3}{*}{ Summer } & June & $20,21,22,23$ & $01,11,16$ \\
\cline { 2 - 4 } & July & $24,25,26,27$ & 18,21 \\
\cline { 2 - 4 } & August & $28,29,30$ & 25,05 \\
\hline \multirow{3}{*}{ Autumn } & September & $31,32,33,34$ & $12,11,15$ \\
\cline { 2 - 4 } & October & $35,36,37,38$ & $05,11,12$ \\
\cline { 2 - 4 } & November & $39,40,41,42$ & 04,09 \\
\hline
\end{tabular}

TABLE I: Dates of the 70 SST images used in this study, covering the 4 seasons of the years 2007 (daily) and 2008 (weekly).

total of 70 SST images of Advanced Very High Resolution Radiometer (AVHRR) sensor, obtained during the years 2007 and 2008.

The whole database has been acquired and processed at the Royal Centre of Remote sensing (CRTS) of Morocco, including the generation of cloud and land masks. The SST images are radiometrically calibrated so that each pixel data contain temperature information in Celsius degrees. The cloud overlay is generated using the multispectral criterions, to perform the classification of pixels as cloud pixels [18].

The images used in this study are selected using the scientific and technical knowledge of the Moroccan coastal upwelling. Indeed, the image is retained for the analysis if it has at least $70 \%$ of valid information (no clouds or missing pixels) between the coast and $200 \mathrm{~km}$ offshore [13] in a direction perpendicular to the coastline.

After rejecting the images with heavy cloud occlusions over the area of interest, the size of each SST image is $714 \times 750$ pixels with spatial resolution of $1.1 \times 1.1 \mathrm{~km} .24$ images among the 70 used in this work represent daily images selected from the year 2007, and in order to validate the applicability of our algorithm in the case of weekly synthetic SST product, 46 weekly images of the year 2008 are also selected and included in our benchmark. The weekly images are generated using the maximum value composite procedure [10] when only the maximum pixels values in 8 daily images are retained. This approach allows both, eliminating a maximum number of pixels contaminated by clouds and reducing the large number of images daily processed [19]. Table I shows the date of the images used in this study. It should be stressed that in the third column of Table I, each date represent the weekly synthetic composite image which is constructed using 8 daily images.

Additionally, a color scale of 26 levels is applied to each image to help users and oceanographers for visual inspection of the main frontal boundary separating the cold waters near the coast and warmer offshore waters. Fig. 1 shows two SST images selected from our database of 70 images, representing daily (Fig. 1 (a)) and weekly (Fig. 1 (b)) images. The pixels with gray color on the right side of the images correspond to land, whereas the white pixels in the left side correspond to

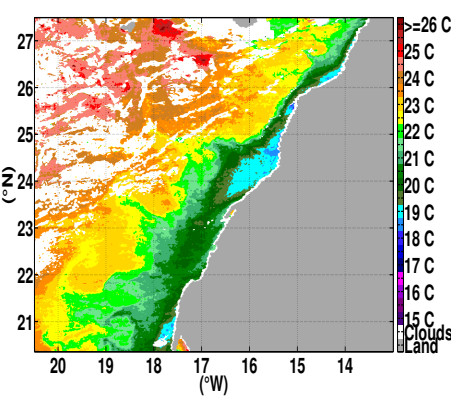

(a)

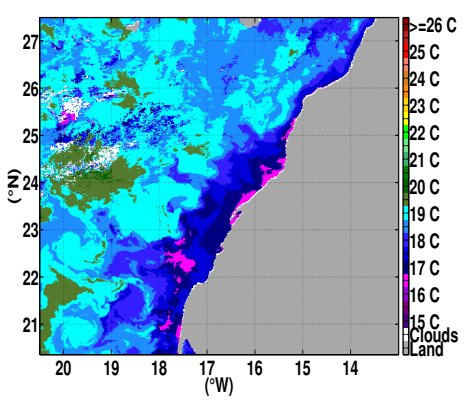

(b)
Fig. 1: Daily and weekly SST images obtained respectively on (a) 2007-09-11 and (b) 2008-01-1.

cloud regions on the ocean

\section{THE PROPOSED APPROACH}

The coarse segmentation of upwelling region is performed in 4 steps: 1) classification and labeling the original SST images using the Otsu's method with the number of clusters varying from $C_{\min }$ to $C_{\max } ; 2$ ) selection of the appropriate number of clusters, $C^{*}$, resulting from compact and well-separated groups by applying two well-known validity indices; 3 ) application of simple threshold to the labeled image in order to detect the area covered by the upwelling waters; 4) filter all the noisy residual structures not belonging to upwelling waters and then extract the final upwelling region.

\section{A. Clustering technique}

Clustering [11] is an unsupervised classification method when the only data available are unlabeled, and no structural information about it is available. The main aim of clustering is to detect the homogenous groups in data by classifying the pixels according to similarities among them.

The existing clustering methods can be grouped into two different strategies, hard [11] and fuzzy [3]. Hard clustering methods are based on classical set theory, and require that an object either does or does not belong to a cluster. Fuzzy clustering methods allow objects to belong to several clusters simultaneously, with different degrees of membership.

In [19], Otsu and Fuzzy $c$-means algorithms are respectively used, as the underlying hard and fuzzy strategies, to deal with the problem of identifying the upwelling area in coastal ocean of Morocco using SST images. The classification results, obtained by these well-known methods are nearly similar with satisfactory results. The Otsu's method has indeed the advantage to be highly efficient and demand less computation time when the number of classes is 2 [19].

Otsu's method is a clustering-based image thresholding, based on the selection of the optimal thresholds from the gray-level histogram of an image that maximizes the betweenclass variance [15]. Otsu defines the between-class variance 


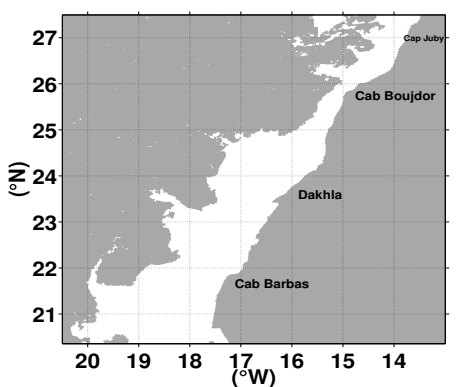

(a)

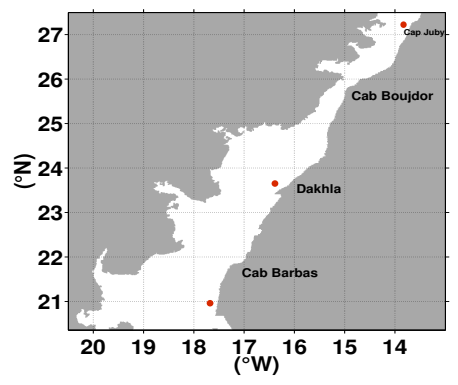

(c)

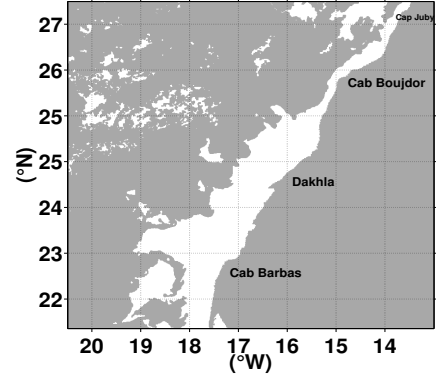

(b)

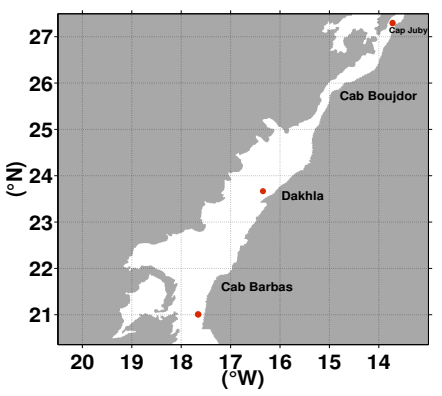

(d)
Fig. 2: (a),(b): binary images showing the area covered by the upwelling waters; (c),(d): application of the region-growing process to the binary images (a) and (b), using three seed points shown in red color overlaid the binary results.

using the discriminant analysis based on statistics of the onedimensional histogram [9].

In our case, the Otsu's method is used to partition each SST image by setting the number of clusters varying from $C_{\min }=2$ to $C_{\max }=7$, and the optimal number of clusters $C^{*}$ is determined using the validity indices. The $C_{\max }$ is fixed to 7 , since there is no change in the mean temperature of the main clusters beyond 7 clusters.

\section{B. Optimal number of clusters}

Most clustering algorithms need to know the number of clusters to look for. The cluster validity refers to the problem of finding the optimal number of clusters, which helps to discover the distribution of patterns and interesting correlations in data [20]. In particular, the validity indices are largely used as a mechanism to determine the appropriate number of clusters in each data [20]. In the literature, Davies-Bouldin (DB) [7] and Dunn's (DI) [8] indices are frequently used in the hard clustering methods for the purpose of determining the good number of clusters [16].

Davies-Bouldin index is a function of ratio of the sum of within cluster scatter to between cluster scatter [16]. In general, we find the optimal cluster number $C^{*}$ by solving $\min _{C_{\min } \leqslant C \leqslant C_{\max }} D B(c)$ to produce the best clustering performance for data. Dunn index is a ratio of within cluster and between cluster separations and it's originally proposed to use for the identification of compact and well-separated clusters. The number of clusters that maximizes the DI index is taken as the optimal number of clusters, $\max _{C_{\min } \leqslant C \leqslant C_{\max }} D I(c)$.

In the proposed work, we apply the validity indices defined above, to the complete Otsu's partition results $\left[C_{\min }, \ldots, C_{\max }\right]$, and the extremum values (maximum for DI index and minimum for DB index) of these indices indicate the good number of clusters.

The results of the DB and DI indices applied to the original SST images in Fig. 1 have shown that the cluster number 2 is the correct number of clusters for the corresponding two images and for all the database (70 images) used in this study.

\section{Upwelling detection}

Once the labeled image is generated with the optimal number of clusters, $C^{*}$, the next step consists of identifying the cluster which represents the upwelling area. For this purpose, the cluster with the lowest mean value is flagged to be the upwelled region [19], based on the fact that the upwelling waters are usually characterized by low temperature values near the coast compared to the offshore warmer waters. The binary results of the upwelling region, for the SST images in Fig. 1, are respectively showed in Fig. 2(a) and (b).

\section{Post-processing}

After identifying the area covered by the upwelling waters, the remaining problem concerns the elimination of fine and noisy structures in offshore waters not belonging to the upwelling region near the coast. These structures are typically due to the scattered clouds not properly masked by the cloud detection algorithm used in this study [18]. In this sense, the region-growing algorithm is applied to the binary images, in Fig. 2(a) and (b), in order to remove the remaining isolated pixels [19].

The region-growing algorithm [4] is a segmentation method, which examines the neighboring pixels of initial points called the seed points, and determines whether the adjacent pixel should be added to the region. However, the region-growing algorithm require the selection of adequate initial points in each image, in order to have an admissible segmentation results. In the case of upwelling segmentation, the selection of these initial points is based on the scientific knowledge and well-known spatial distribution of Moroccan upwelling coast. In fact, three initial points corresponding to upwelling sources are chosen near the coastline to take into account the continuity of upwelling along the coast and based on the fact that all the segmented pixels pertaining to the upwelling must have connectivity to the coastline (Fig. 2(c) and (d)).

\section{EXPERIMENTAL RESULTS AND ANALYSIS}

\section{A. Oceanographers evaluation}

The effectiveness of the proposed approach has been tested on 70 AVHRR SST images covering the southern Moroccan Atlantic coast of the years 2007 and 2008.

It must be noted that, the in-situ measurements, e.g., buoys data, can give us a sounder support to the results obtained 


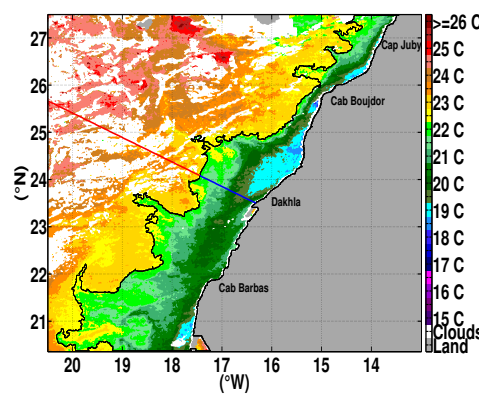

(a)

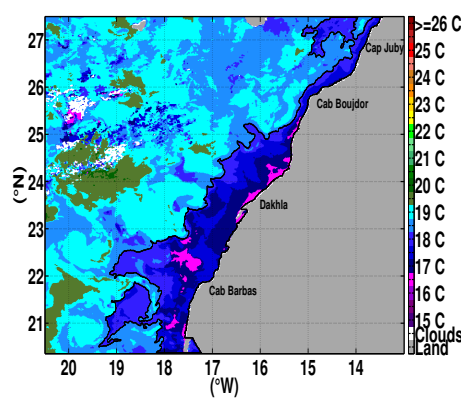

(b)
Fig. 3: Upwelling zone automatically contoured (black contour) by the proposed approach using the SST image in Fig. 1. (a) shows an example of a radial (segment with blue and red color) in which the extension and the intensity of upwelling is calculated.

by the proposed approach. However, these measures are very complex to establish and would be extremely challenging for a use in coastal zone context, because of lack of these measures for all the satellite images and for every specific region in the study area. In this sense, it is a well-known fact that validation in the case of ocean data is often and truly performed by assessing the results by professional oceanographers [12] [17] [19], which has been done in the case of this work.

Throughout this evaluation, we used 4 grades: "Bad", "Poor", "Good" and "Excellent". The grade "Bad" is attributed when the upwelling region is not well delineated by the proposed algorithm, and "Excellent" is assigned when the area is correctly identified in each SST image. Indeed, the grade "Bad" corresponds to the range between $[10 \%$ and $30 \%$ ], the grade "Poor" range from [40\% to 50\%] and "Good" corresponds to the values between [60\% and 70\%], and finally the grade "Excellent" range from [80\% to $100 \%]$.

The results revealed that $44 \%$ and $48 \%$ marks are "Excellent" and "Good", respectively, and the value of $7 \%$ is attributed to the grade "Poor". Most importantly, the results have shown that the grade "Bad" is not attributed at all.

In the whole SST images analyzed in this study (70 images), the value of $92 \%$ is reached by the two grades "Good" and "Excellent" together. These results show that the proposed approach delimitates correctly the area of upwelling cold water, and provides an accurate segmentation results for the majority of images used in this study. Fig. 3 shows the SST images in Fig. 1, where the upwelling boundary is automatically contoured by the proposed approach. The marks attributed to these images are "Excellent" (Fig. 3(a)) and "Good" (Fig. 3(b)).

\section{B. Analysis of seasonal variability of upwelling activity}

In the following subsection, we have addressed a seasonal variability of upwelling area and upwelling intensity over the region of interest, using the 70 SST images.
The proposed methodology used to calculate the upwelling intensity has been inspired from the work reported in [1], where the upwelling index is defined as a simple difference between the maximum temperature $\left(S S T_{\max }\right)$ located in offshore waters and the minimum temperature $\left(S S T_{\text {min }}\right)$ detected in onshore for each latitude [14].

In this study, we follow the same philosophy as in [1] but we do not search for the minimum temperature value (for each latitude) between the coast and $50 \mathrm{~km}$ offshore, but rather, we look for the $S S T_{\min }$ inside the upwelling fringe detected by our proposed methodology for each image. The width of upwelling area has also been calculated, for each latitude, for the purpose of finding the seasonal variability of upwelling extension along the Moroccan Atlantic coast.

Fig. 3(a) shows an example of a radial in which the extension and the intensity of upwelling is calculated. In this figure, the segment with blue and red color over the radiale correspond to the effective ranges in which the $S S T_{\text {min }}$ and $S S T_{\max }$ values are respectively sought.

The seasonal variability is analyzed by averaging the intensities and extensions of upwelling for the whole latitude in a given season. Fig. 4(a) and (b) shows respectively the variability of upwelling extension and upwelling intensity over the study area, which is limited to the southern Moroccan Atlantic coast spanning from $20^{\circ} 50^{\prime}$ to $27^{\circ} 52^{\prime} \mathrm{N}$ and $13^{\circ} 10^{\prime}$ to $20^{\circ} 10^{\prime} \mathrm{W}$.

Fig. 4(a) shows that the upwelling extension is spatially variable all around the year with maximum values $(250 \mathrm{~km})$ at the latitude $22^{\circ} 50^{\prime} \mathrm{N}$ during the winter season. This maximal extension is due to the strong activity of the Azores anticyclone over the study area during the winter, generating a northeasterly wind responsible of upwelling activity. In contrast, during the summer, the upwelling extension is lowest, mainly because of the displacement of the Azores anticyclone to the northward during this season, giving way to the westerly and southwest winds, which are not favourable for upwelling activity.

On the other hand, the upwelling intensity for the 4 seasons generally present the same tendency along the whole coast (Fig. 4(b)). Indeed, except the north of the study area (from $26^{\circ} 50^{\prime}$ up north) where the upwelling intensity in the summer season are important, the intensity in autumn is maximal along the coast with a peak at the latitude $26^{\circ} 0^{\prime} \mathrm{N}$. Nevertheless, in the spring season, the upwelling intensity shows the lowest values along the coast.

It must be noted that, the upwelling intensity is generally related to the main upwelling front separating the upwelling area near the coast and warmer offshore waters. This intensity depends on the degree of upwelling activity and the pressure applied by the warm waters. In conclusion, the upwelling extension is variable throughout the year with maximum values between the Cap Juby and Cap Boujdor (Fig. 4(a) shows the location of these cap's) during the winter and spring seasons at the latitude $26^{\circ} 80^{\prime} \mathrm{N}$ and between Dakhla and Cap Barbas during the winter at the latitude $22^{\circ} 50^{\prime} \mathrm{N}$. The upwelling intensity for the 4 seasons generally trend together with significant value at the latitude $26^{\circ} 0^{\prime} \mathrm{N}$ (between the Cap Juby and Cap Boujdor) during the autumn and summer. 


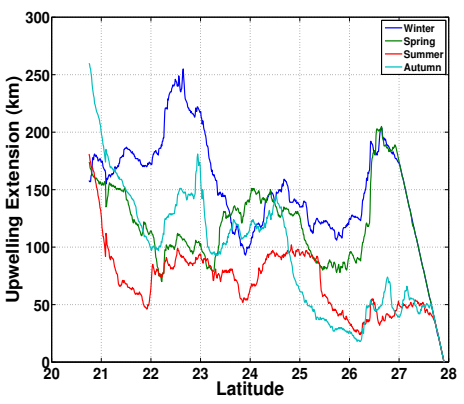

(a)

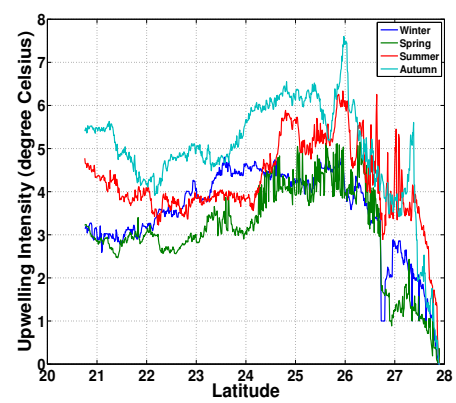

(b)
Fig. 4: Seasonal variability of (a) upwelling extension and (b) upwelling intensity, averaged over the 70 SST images.

\section{CONCLUSION}

This paper deals with the development of a simple algorithm that is able to objectively delineate the upwelling area in Moroccan Atlantic coast using the sea surface temperature images. The implemented methodology is performed in two main stages. The first one with the goal to detect and identify the upwelling region in SST images using the Otsu's method with the number of clusters determined using the DaviesBouldin and Dunn indices. The second step involves the use of region-growing process in order to filter and remove the remaining offshore waters not belonging to the upwelling area, using three seed points selected with respect to the scientific knowledge of Moroccan coastal upwelling. The proposed approach is validated by an oceanographer and it is used to provide a seasonal variability of upwelling activity in the southern Atlantic coast using 70 SST images of the years 2006 and 2007. Regions of high upwelling extension are identified at the latitude $22^{\circ} 50^{\prime} \mathrm{N}$ during the winter season and around the $26^{\circ} 50^{\prime} \mathrm{N}$ during the spring and winter periods. For the upwelling intensity the autumn season show a highest intensity at the latitude $26^{\circ} 0^{\prime} \mathrm{N}$. In summary, the proposed methodology has demonstrated an excellent performance and sounder support to the results already obtained in our previous work.

\section{ACKNOWLEDGMENT}

Thanks is due to Mohammed Faouzi Smiej for the work developed to generate the AVHRR SST images in the Royal Centre of remote sensing.

\section{REFERENCES}

[1] A. Atillah, A. Orbi, K. Hilmi, and A. Mangin. Produits opérationnels d'océanographie spatiale pour le suivi et l'analyse du phénomène d'upwelling marocain. Geo-Observateur, 14:49-62, 2005.

[2] A. Bakun. Fronts and eddies as key structures in the habitat of marine fish larvae : opportunity, adaptive response and competitive advantage. Scientia Marina, 70(S2):105-122, 2006.

[3] G.L. Carl. A fuzzy clustering and fuzzy merging algorithm. Technical Report CS-UNR-101, 1999.
[4] Y. Chang and X. Li. Adaptive image region growing. IEEE Transactions on Image Processing, 3:868-872, 1994.

[5] E. Chassot, S. Bonhommeau, G. Reygondeau, K. Nieto, J. J. Polovina, M. Huret, N. K. Dulvy, and H. Demarcq. Satellite remote sensing for an ecosystem approach to fisheries management. Ices Journal of Marine Science, 68(4):651-666, 2011.

[6] S. Chaudhari, R. Balasubramanian, and A. Gangopadhyay. Upwelling detection in AVHRR sea surface temperature (SST) images using neural-network framework. In IEEE International Geoscience Remote Sensing Symposium, volume II, pages 926-929, 2008.

[7] D. L. Davies and D. W. Bouldin. A cluster separation measure. Pattern Analysis and Machine Intelligence, IEEE Transactions on PAMI, 1(2):224-227, April 1979.

[8] J. C. Dunn. A fuzzy relative of the isodata process and its use in detecting compact well-separated clusters. Journal of Cybernetics, 3(3):32-57, 1973.

[9] K. Fukunage. Introduction to statistical pattern recognition. New York: Academic Press, pages 260-267, 1972.

[10] B. N. Holben. Characteristics of maximum-value composite images from temporal AVHRR data. International Journal of Remote Sensing, 7:1417-1434, 1986.

[11] A. K. Jain and R. C. Dubes. Algorithms for Clustering Data. PrenticeHall, Inc., Upper Saddle River, NJ, USA, 1988.

[12] S. Nascimento, P. Franco, F. Sousa, J. Dias, and F. Neves. Automated computational delimitation of SST upwelling areas using fuzzy clustering. Computers and Geosciences, 43:207-216, 2012.

[13] K. Nieto, H. Demarcq, and S. McClatchie. Mesoscale frontal structures in the canary upwelling system: New front and filament detection algorithms applied to spatial and temporal patterns. Remote Sensing of Environment, 123(0):339-346, 2012.

[14] L. Nykjaer, L. Van Camp, K. Hilmi, and A. Mangin. Interannual variability of upwelling indices along the northwest african coast. Geo Observateur, Spécial Marisy:176-179, 1992.

[15] N. Otsu. A threshold selection method from gray-level histograms. IEEE Transactions on Systems, Man and Cybernetics, 9:62-66, 1979.

[16] M. K. Pakhira, S. Bandyopadhyay, and U. Maulik. Validity index for crisp and fuzzy clusters. Pattern Recognition, 37(3):487-501, 2004.

[17] F. M. Sousa, S. Nascimento, H. Casimiro, and D. Boutov. Identification of upwelling areas on sea surface temperature images using fuzzy clustering. Remote Sensing of Environment, 112(6):2817-2823, 2008.

[18] L. L. Stowe, P. A. Davis, and E. P. McClain. Scientific basis and initial evaluation of the clavr-1 global clear/cloud classification algorithm for the advanced very high resolution radiometer. Journal of Atmospheric and Oceanic Technology, 16(6):656, 1999.

[19] A. Tamim, K. Minaoui, K. Daoudi, H. Yahia, A. Atillah, M. F. Smiej, and D. Aboutajdine. A simple and efficient approach for coarse segmentation of Moroccan coastal upwelling. In Signal Processing Conference (EUSIPCO), 2013 Proceedings of the 21 st European, pages 1-5, Sept 2013.

[20] W. Wang and Y. Zhang. On fuzzy cluster validity indices. Fuzzy Sets and Systems, 158(19):2095-2117, 2007. 